\title{
Action Exercises Engage Students More Fully Than Lectures and Exams
}

\author{
James C Wetherbe (Texas Tech University)
}

KEYWORDS: Entrepreneurship, Teaching Methods.

\begin{abstract}
Editor's Note: Click to download Jim Wetherbe's 260-page book on better communication, "So, What's Your

Point?

(https://eiexchange.com/dist/api/submissions/348/docu ments?file=So\%20What\%27s\%20Your\%20Point.pdf\&d ownload=1) "
\end{abstract}

In the business world, concepts (e.g., entrepreneurial innovations) must be explained to those who are uninformed, skeptical and reluctant to accept new ideas. Traditional classroom lecture/discussion formats followed by quizzes and exams don't prepare graduates for that formidable challenge.

Also, real bosses do not ask employees to take everything off their desk and take written exams to prove they know what they are doing. Bosses don't ask employees to write term papers either. However, they expect employees to have the ability to make meaningful contributions to business conversations and meetings and to make convincing management presentations and management reports.

\section{Technique Lags Behind Technology}

When a new technology is invented, it tends to be perceived and used in the old ways and only later does innovation in technique occur. That is why the automobile was originally called the horseless carriage - the emphasis being on what was missing.

When ATM's were first deployed they were located within banks and available only during banking hours. Only later did the terrifying (to bank management) idea of leaving cash in unattended ATM's in convenient locations available $24 / 7$ take hold.

When PC's were invented, they were primarily used as an enhanced typewriter for secretaries. It was a status challenge to get executives to have a keyboard on their desk, but the proliferation of information tools and reporting eventually won over the executive suite. Today, it would be odd to find an executive without a PC within reach.

\section{Is Lecturing Obsolete?}

Lecturing, a tool of my professorial occupation, was developed before the invention of the printing press. Professors would read their notes to students, who would diligently copy them and through this tedious process create their own textbook. Even though book publishing is now a prolific industry, many professors continue to lecture as their primary teaching tool.

Does it make sense to have the same professor(s) lecture on the same content repeatedly when it can be captured on video, or even higher-quality video than a talking head, as seen on the History Channel? This is a key advantage of online teaching — but at the loss of rich applied learning experiences.

I and many of my colleagues moved away from lecturing years ago. Why have students read a textbook if we are going to lecture on it? I used this paradox to my advantage as a working college student with time constraints. I noticed professors could not help themselves - they talk mostly about what they consider to be important. If I didn't have time to read the book, I took copious notes and used them to study for exams-another archaic tool.

Some professors ask questions of students in class, which ironically often cripples students' ability to truly explain a concept. Why? Students are explaining to the professor, who already knows the answer and consequently often cuts them off once there is confirmation of knowledge. Evaluation of learning is typically achieved through quizzes and exams.

\section{A Real-World Alternative}

An innovative applied learning approach is an alternative to traditional lecturing and exams. Student 
assignments are Collaborative Action Learning Exercises that simulate how they'll apply that knowledge in the real world. Collaboration includes working in teams, which is more often than not the case in the business world.

Whether using text/chapter or project-oriented courses, action exercises are appropriate.

\section{Traditional Text Action Exercises}

When using a textbook, it is easy to convert traditional discussion questions at the end of the chapter into action exercises. For example, a discussion question such as:

"Define artificial intelligence and its major features" can be converted as follows: "The manager of product innovation has asked your team to meet with her to share your thoughts on how artificial intelligence could be used to improve customer service."

Or a discussion question such as, "Discuss the role websites play in internet competitiveness" can be converted to: "The manager of marketing has asked your team to review highly-regarded websites such as Amazon.com and determine the key features needed in a website for a new start-up company."

Discussion questions can be combined as well. For example, the previous two discussion questions can be combined to create the following action exercise: "The managers of product innovation and marketing have asked your team to come up with ways artificial intelligence could be used to enhance the website for a new start-up venture."

For each action exercise, the student teams engage in meeting simulations where the instructor assumes the role of a manager, customer, investor, etc. When necessary, the instructor can temporarily put on his or her teaching hat. During this time the instructor can ask the class for suggestions for the team and, when needed, provide direct instruction to ensure concepts are understood.

\section{Project-Oriented Classes}

For project-oriented classes, teams have weekly meetings to provide status updates on their respective projects. This begins with a conceptual idea which includes an "elevator pitch" of the product or service idea.
Throughout the semester, each project's steps include initial proposals, schedules, budgets, prototypes, etc. and conclude with a management report and a final presentation, at which time the class serves as an interactive audience.

\section{Class Scheduling and Peer Dynamics}

In a three-hour class that meets twice a week, one class can be spent on preparation/feedback and the other for five meetings/presentations. Ten teams divided into two to four students allows a manageable class size of 20 to 40 students. This allows five teams to present each week, with the non-presenting teams to provide peer evaluation feedback.

In this approach to learning, students are not afforded the anonymity of written exams. Their knowledge and preparation is on display for the entire class during weekly presentations. This proves to be a strong motivator because students are highly concerned about impressions they make on their peers.

A major advantage to this approach to teaching is it eliminates any opportunity or concern for cheating. Student preparation and knowledge are evident.

\section{Preparation and Feedback Class}

Preparation for these activities includes class discussion-and as a last resort, clarifying minilectures, along with homework and preparation of project deliverables. Teams work on their projects during class, during which time the professor can be a roving consultant. Use of the internet, which has turned life into an open book exam, is encouraged as an additional source for content.

If the professor/consultant perceives that much of the class doesn't understand a key concept (e.g. developing a budget or project plan) he or she has two productive options: a team that has mastered the issue can explain to the class, or the professor as a last resort can provide a mini-lecture/tutorial.

Use of email and texting as a means of communication between individuals, project team members, and the instructor is highly recommended. Each student is expected to check his/her email account daily. This convenient form of asynchronous communication has virtually eliminated the need 
for traditional office hours.

Once those teams working on next class presentations are at work, peer ranking and evaluation feedback as outlined below can be discussed discreetly with each team that presented the previous class. This can be done by stepping outside the classroom to a more informal setting, even in the professor's office if it is conveniently located.

\section{Meeting/Presentation Grading?}

This is a competition from which grades are determined. The teams are ranked from first to fifth each week through the "crowd-sourced" peer review, including forced ranking supported by individual comments for each student as qualitative feedback. Students are comfortable with crowd-sourced feedback as it is used on many TV competitions such as The Voice or American Idol, or even by the number of likes they get on an Instagram post.

As a rule, the top two teams get an A for the week, the third and fourth a B and the last place team a C. Each team gets reviews, including peer comments and ranking. At the end of the semester, each team is allowed to select an MVP. That student's average team grade can then be elevated one letter grade or to an $A_{+}$ for an A team. In practice this results in half A's and B's by the end of the semester. Students not sufficiently motivated by internal motivation or peer pressure to achieve A or B level performance drop the class within a few classes which is usually one to two students a semester.

Classroom performance in the action learning exercises is used for evidence of learning and knowledge. In addition to the weekly evolving of their idea presentations, at the end of the semester, students prepare a final presentation and a Management Report of their initiative. These are peer reviewed as well via crowd-sourced feedback.

During class presentations, the professorial role can switch back and forth from that of a role-playing manager and instructor as needed.

\section{Communications Skills Training is a Necessity}

Students who are used to traditional exams are not prepared to demonstrate their knowledge or idea through persuasive communication. This is an additional skill set that needs to be developed as part of the learning experience.

To assist communication for action exercises-including weekly class meetings, presentations and reports -complimentary access is provided on EIX to "So, What's Your Point?

(https://eiexchange.com/api/submissions/348/document s?file=So\%2C\%20What\%27s\%20Your\%20Point\%3F.p df\&download=1) " This book provides an innovative, structured approach to communication, one that helps students navigate conversations or presentations and produce mutually beneficial outcomes. It is particularly helpful with Collaborative Action Learning Exercises for class and future careers.

Key skills developed in the book include how to:

1. Understand and appropriately prepare for an audience of one or more

2. Grab and retain attention by use of an opening "hook" question and social contract, which is fulfilled via the conversation/presentation

3. Skillfully probe throughout conversations and presentations to ensure understanding and focus on target topic

4. Use problem/solution format to persuasively present ideas, innovations and courses of action

5. Overcome objections through rephrasing to ensure understanding and, as needed, clarifying and simplifying through use of alternatives and compromise

6. Overcome reservations and doubts through reassurance and providing substantiating evidence

7. Use indirect and direct probing to explore and identify issues of concern or hesitation that are not being expressed in a forthcoming manner.

8. Resolve conflict through negotiation and without argument

9. Effectively transfer communication skills that apply to email, text, memos, letters and management reports

10. Use body language that projects openness, reassurance, confidence, acceptance and cooperation

11. Read and respond to body language that projects defensiveness, nervousness, frustration, suspicion and boredom

12. Conclude conversations, presentation and 
reports through summarizing key points of agreement and finalizing clear courses of action, including desired outcome, responsibility and rewards

An excellent alternative book to "So, What's Your Point?" for developing persuasive communications skills is "Getting to Yes"(https://www.amazon.com/GettingYes-Negotiate-Agreement-Without/dp/0743526937) by Fisher, Ury and Boutsikaris.

At the beginning of the semester students are given the assignment to read the communication skills book, and one class is spent on discussing and practicing the skills in the book(s). Communications skills become an ongoing dimension of the learning process throughout the semester, using the book as a reference tool to refine skills.

Through this parallel education process, students learn a specific interpersonal communication process along with substantive content when conducting the action learning exercises, via role playing with the instructor and class while presenting progress reports.

Peers and the instructor consider both process and content when evaluating and grading each team. The process considers "how well" the students communicate, and the content considers "what" is communicated. Role-playing sessions are recorded on digital video and subsequently shared with participating students for feedback and learning reinforcement.

A good option for capturing videos is to have a student within the audience record the meeting using a team member's cell phone. Alternatively, a video camera can be used.

Initial communication efforts are a challenge, as students are used to answering questions from a professor who already knows the answer as opposed to someone who does not. So, to reinforce, two types of learning are occurring in parallel: one is how to develop and refine a proposal/concept; the other is learning how to communicate more effectively

Both improve over the semester concurrently. By the end of the semester, students learn how to communicate like business professionals rather than students. This parallel learning process of course takes time, which is made possible through getting rid of traditional lectures and exams.

\section{From Concept to Final Presentation}

In TV advertising, every second counts - especially during peak viewing times such as Superbowl Sunday when a 30-second ad costs millions of dollars. In the entrepreneurial world, the stakes can be at least as high. The ability to attract attention and financing often starts with a simple explanation - called "the elevator pitch" -- of how a product or service solves a problem.

Here's a lesson from the world of television that entrepreneurs can use to hone that pitch. Advertisers use a simple problem/solution format. They present the problem -- whether it's bad breath, a stain on a shirt, wanting to meet someone to date, car trouble, etc. -and immediately follow that with a solution. The problem is the "hook" that gets our attention then focuses it on the solution.

For example, a pitch that promotes EIX would use this problem/solution format:

\section{Problem}

Publishing using traditional entrepreneurial journals takes far too long because of time-consuming review, selecting/scheduling articles and limited print space. As a result, it can take one to four years for good research and ideas to see the light of day.

\section{Solution}

This can be remedied by replacing print publications with an online social-media platform where good ideas and highly qualified reviewers can conveniently identify and communicate with members of the editorial board. Once accepted, articles can be published immediately, reducing the publication cycle from years to weeks.

\section{Discussion}

This "elevator pitch" takes less than a minute but if effective creates interest and curiosity. They are key for communication during the action exercises. Unlike a TV advertisement, a problem/solution format in an action exercise meeting allows for questions to be asked or challenges to be made afterwards such as: "Print journals are more prestigious than online journals."

Through communication training students can learn that a thoughtful question can diffuse such a challenge by asking a question such as: "Where you aware that brick and mortar stores said the same thing about Amazon.com?" 
The goal of the pitch is to ensure that discussion takes place so the idea can move forward.

\section{Power of Problem/Solution Format}

A problem or opportunity/solution format is the primary framework for both the Collaborative Action Learning Exercises and the Management Presentation and Report. As students learn to communicate solutions to problems; they advance beyond providing basic "classroom" definitions of concepts, techniques, and technology. This is an invaluable enhancement in developing and applying critical thinking skills.

The ability to articulate complex issues clearly has been, and will be even more so in the future, a fundamental element of business student success. It is ranked as the number one skill of successful business executives. Very few business schools effectively emphasize communication skills, to the distinct displeasure of nearly every corporate executive I know. This, of course, is a major opportunity and differentiator for business education.

It is truly tragic how many breakthrough technologies were initially or completely missed by companies such as NCR (main frame computers), IBM (mini-computers), Xerox (Windows), DEC (PC's), HP (Apple) and Microsoft (cellular) because of communication failures--management was not convinced of the opportunity. These illustrate the compelling need for effective communication within even top corporations. Accordingly, communication has always been a priority in my teaching and consulting.

Students thrive on examples to illustrate an end-product for an innovation proposal.

An example of presenting an idea using the problem/solution format is presented below. This is a copy of the communication sent to Dick Schulze, Founder of Best Buy and the Schulze Foundation, and is used as a handout in class. It illustrates how an initial idea can blossom from an elevator pitch to a written proposal. This correspondence led to the creation of EIX.

\section{Example}

Dear Dick,

It was good visiting with you last week. Many thanks for your feedback on Entrepreneurial and Innovation
Exchange, or EIX, as an innovation for communication of thought leadership for students, faculty and practitioners of entrepreneurship.

As per your request, below is a summary of our discussion and a request to draw from the existing Texas Tech University Best Buy grant to create EIX.

As we discussed, to be a premier program, the Schulze School of Entrepreneurship needs a world-class communication vehicle to facilitate thought leadership. In the past this would be achieved with a print journal (e.g., Harvard Business Review at Harvard, MIS Quarterly at Minnesota). Traditional print journals have limitations, which is why many are adding online versions with blogs such as HBR.ORG and Businessweek.com.

The Schulze School can add value and innovation by skipping the print stage and making a pure internet play, with functionality far beyond those of other journals, and achieve superior economics in the process. It is an "entrepreneurial approach" to facilitating entrepreneurial thought leadership.

Here is a summary of the key points.

$\begin{aligned} & \text { Problems with } \\ & \text { Journals }\end{aligned}$

Problems and limitations of current print/monologue journals include:

1. Prolonged decision on publication due to blind review process (up to a year)

2. Page constraint resulting in delayed publication (usually two years)

3. One-way print monologue communication; no opportunity for dialogue among readers and author

4. Subscription to print journal and/or copy of article is required to share with others

5. Access to references requires additional effort

6. Articles primarily academic, which can limit application to practice

7. No objective assessment of the value of the articles to assist readers

8. Limited to printed articles as the primary capability, and 
9. No opportunity to engage with authors in person

\section{Solutions and Innovations provided by EIX}

EIX becomes a hybrid learning resource for one stop "shopping" for thought leadership on entrepreneurship resolving the problems above by:

1. Prolonged blind review process replaced with transparent endorsement process. Authors can choose from a select pool of highly regarded scholars or entrepreneurs. In this model the author(s) reach out to thought leaders to review and endorse manuscripts. Three endorsements from "endorsed" reviewers grants automatic publication. To ensure quality, endorser's names are printed with the article so their reputation is part of the equation.

2. Page constraint is automatically resolved by use of web publication instead of printed pages.

3. One-way communication limitation with printed journal is replaced with online blogs for comments and debate.

4. Subscription to print journal limitation is resolved by sharing online links to journal.

5. Access to article references is resolved with online links.

6. Since page limitation is not a concern, EIX has the capacity to publish more articles which allows for two sections--one for scholarly academic and one for applied articles (e.g., HBR style). Applied articles will often be written by successful entrepreneurs.

7. To overcome the "too many articles and not enough time" challenge for readers, EIX will have a ranking system that points readers to the most read and liked articles on different topics.

8. Besides just articles, EIX will include video interviews of entrepreneurs.

9. To overcome lack of opportunity to engage with thought leaders in the field of entrepreneurship, awards for best articles (as determined by blogs and "likes") will be granted. An annual EIX conference will be hosted by the Schulze School with award-winning authors invited to the Twin Cities each summer. This will become a prestigious, premier event to engage with thought leaders in entrepreneurship research and practice.

\section{How do we get started?}

All we need is a founding Editor-in-Chief and funding, both of which are available.

As we discussed, I would be honored to take on the founding Editor-in-Chief role.

Editors of journals are not necessarily located at the home institution of the journal. For example, after several years of the Editor for the MISQ being at Minnesota, we would appoint subsequent editors from other universities to establish it was a journal of the field of MIS. The Schulze School would appoint new editors in the future, say every three years, and still retain ownership of EIX.

Support costs for web development, promotion and technical editing can be easily covered. You will recall BBY gave a grant to Texas Tech for internet buyer research which has been drawn from for mutually agreed-upon research Internet research projects for the past 13 years. There is over $\$ 100,000$ still available, which could be purposed for EIX.

All that is needed is a letter from BBY authorizing use of the funds to cover operating costs to start the "journal."

EIX can be up and running and building reputation for the Schulze School within six months.

Please let me know if you need additional information to approve moving forward.

Best Regards,

James C. Wetherbe, $\mathrm{PhD}$

\section{Final Presentation and Report}

Once students prepare a written proposal as illustrated above, they have the content to prepare a formal presentation and management report. Techniques and tools for preparing both are provided in Chapters 16 and 17 in "So, What's Your Point?" available through EIX here.

The final presentation, which is the surrogate for a final 
exam, is presented to the entire class to provide a full audience. As with weekly meeting exercises, the final presentations are peer ranked to provide the full experience of competition.

\section{Conclusion}

Observing students transform into professional caliber communicators who can persuasively explain how to apply knowledge to solve problems is rewarding. The resulting growth in their confidence is striking.

Perhaps the best way to conclude this article is to illustrate how students respond to action learning.

The State of Texas mandates public access to university teacher evaluations. The following quotes are from last semester teacher evaluations and are representative of what have been reported for decades:

- The class was an amazing experience for me and honestly a lot of classes should be taught more like this because it makes the student be aware of what's going on in class rather than to be bored out of his/her mind in a lecture based class. I really enjoyed that you made this class the way it is based upon real world job because I can relate with what you said about the analogy in the beginning of the semester. Thank you.

- Professor made this class challenging while still keeping his students engaged in learning. i feel like I learned valuable skills in this class that I can apply to my life in the future as well as the present. Jim's teaching methods are unorthodox, but they are far more effective than the classic lecture system. overall, it was a great class.

- Great professor and learning experience. this class got me out of my comfort zone and I feel that by taking this class with professor Wetherbe it will better prepare anyone for the future.

- He is by far the best instructor I have ever had and learned valuable things that I will be able to use in a career.

- I have learned more in this class about real life job skills than any other teacher combined. Very interesting man and had advice and real life situations for everything. Inspired to be like this man.

- I loved the format in which this course was taught even though it was intimidating at first.

- He definitely has a different way of teaching but was fantastic! His style helps student learn while applying it to a business world situation. He is incredibly insightful and I believe that he wants to see every student succeed and become successful in whatever they do. Since he also has experience outside the classroom (and a lot of it) applying the information we are learning, it helps students see why his class is so applicable to a business environment. I recommend him to everybody needing to take the class.

- Out of all courses I have ever taken, this one has prepared me for the business world more than anything else, and given me great knowledge to implement in my career.

Additional Search Terms: entrepreneurship courses, teaching ideas, teaching resources, classroom ideas, entrepreneurship classes, business schools, business school classes, entrepreneurship students, professors 